\title{
Characteristics of sound propagation in shallow water over an elastic seabed with a thin cap-rock layer
}

\author{
Alec J. Duncan, ${ }^{\text {a) }}$ Alexander N. Gavrilov, Robert D. McCauley, and lain M. Parnum \\ Centre for Marine Science and Technology, Curtin University, G.P.O. Box U1987, Perth, Western Australia \\ 6845, Australia. \\ Jon M. Collis \\ Colorado School of Mines, 1500 Illinois Street, Golden, Colorado 80401
}

(Received 31 August 2012; revised 15 March 2013; accepted 7 May 2013)

\begin{abstract}
Measurements of low-frequency sound propagation over the areas of the Australian continental shelf, where the bottom sediments consist primarily of calcarenite, have revealed that acoustic transmission losses are generally much higher than those observed over other continental shelves and remain relatively low only in a few narrow frequency bands. This paper considers this phenomenon and provides a physical interpretation in terms of normal modes in shallow water over a layered elastic seabed with a shear wave speed comparable to but lower than the water-column sound speed. A theoretical analysis and numerical modeling show that, in such environments, low attenuation of underwater sound is expected only in narrow frequency bands just above the modal critical frequencies which in turn are governed primarily by the water depth and compressional wave speed in the seabed. In addition, the effect of a thin layer of harder cap-rock overlaying less consolidated sediments is considered. Low-frequency transmission loss data collected from an offshore seismic survey in Bass Strait on the southern Australian continental shelf are analyzed and shown to be in broad agreement with the numerical predictions based on the theoretical analysis and modeling using an elastic parabolic equation solution for range-dependent bathymetry.
\end{abstract}

(C) 2013 Acoustical Society of America. [http://dx.doi.org/10.1121/1.4809723]

PACS number(s): 43.30.Ma, 43.30.Bp [NPC]

Pages: 207-215

\section{INTRODUCTION}

Substantial areas of continental shelves around the world are covered with a layer of relatively soft unconsolidated sediments, such as sand, clay, or silt, in which the shear modulus is sufficiently low that the acoustic medium of the sediment can be reasonably well approximated by a fluid. The additional loss mechanism caused by the shear waves in the sediment is accounted for by an increase in the compressional wave attenuation coefficient. Over large areas of the continental shelves this soft sediment layer is thick enough that shear waves in the underlying basement can be ignored when modeling sound propagation in the water column, leading to all-fluid seabed models. Sound propagation over fluid seabeds in shallow water has been thoroughly considered in many publications, from the pioneering work by Pekeris (1948) to the most recent book on shallow water acoustics by Katsnelson et al. (2012). However, there are many places on the world's continental shelves where the unconsolidated sediment layer is thin or even absent for various reasons, such as low sediment discharge from rivers and highly dynamic ocean environments, resulting in strong sediment transport exposing underlying sedimentary rocks. In such conditions, the effect of shear in the seabed can have a substantial effect on acoustic propagation in the overlying water column.

Acoustic reflection from a layered elastic seabed was analyzed by Brekhovskikh (1960), and Ewing et al. (1957)

\footnotetext{
a) Author to whom correspondence should be addressed. Electronic mail: a.duncan@cmst.curtin.edu.au
}

considered acoustic propagation in the water column over an elastic seabed with an emphasis on interface waves. Victor et al. (1965) theoretically modeled impulsive sound propagation in a fluid layer overlying a layered solid whereas Tolstoy and Clay (1966) considered the dispersive characteristics of normal modes propagating in water over an elastic basement. Ellis and Chapman (1985) analyzed phase and group velocities and attenuation of normal modes in shallow water channels, where the shear wave speed in the seabed was lower than the sound speed in water. Using an adiabatic mode approximation, Arvelo and Überall (1990) modeled the influence of elastic waves in the seafloor and varying bathymetry on acoustic transmission loss in shallow water. However, neither Ellis and Chapman (1985) nor Arvelo and Überall (1990) considered the frequency-dependence of lowfrequency sound propagation over an elastic bottom in detail. Lobanov and Petukhov (1993) used the theoretical derivations made in Ellis and Chapman (1985) to explain the space-frequency pattern of the sound field measured from a broadband acoustic source in shallow water over bedrock, but only considered the case in which the shear wave speed was higher than the water column sound speed.

A shallow water environment with a shear wave speed in the seabed comparable to but smaller than the water column sound speed is typical for certain areas of continental shelf where the top layers of the seabed consist of limestone, a sedimentary rock composed of partly or fully cemented calcite and aragonite grains. Duncan et al. (2009) modeled low-frequency sound propagation over calcarenite, which is a type of soft limestone that makes up the majority of the western and southern continental shelves of Australia. They 
assumed the compressional and shear wave speed in calcarenite to be $2800 \mathrm{~m} / \mathrm{s}$ and $1400 \mathrm{~m} / \mathrm{s}$, respectively, and found that the transmission loss at low frequencies was relatively low only within narrow frequency bands just above the critical frequencies of low-order modes, with these frequencies being governed primarily by the water depth and compressional wave speed in the calcarenite. Chotiros and Isakson (2010) examined sound propagation in the same environment, but using a Biot-Stoll poroelastic model of calcarenite, rather than the elastic model assumed by Duncan et al. Their numerical prediction did not show the narrow frequency banding in the transmission loss predicted by the elastic seabed model; however, their results were inconclusive because a number of their seabed model parameters were highly uncertain due to a lack of detailed information about the properties of the material.

Acousto-elastic properties of limestone vary greatly depending on its method of formation, composition, and degree of cementation. In the case of the Australian continental shelf, the calcarenite was formed when it was exposed to the atmosphere during past periods of low sea level. Exposure of calcium-carbonate rich marine sediments to fresh water from atmospheric precipitation resulted in the calcium carbonate in the top layer of sediment partly dissolving, penetrating deeper as a pore fluid and then re-crystallizing, cementing the remaining sediment grains together. This process depended on several environmental factors and was not constant in time. As a result, calcarenite seabeds assume a layered structure with geoacoustic properties changing abruptly, and non-monotonically, with depth. Once re-submerged by rising sea level, wave action and/or currents often eroded the seabed until a relatively hard layer was reached. It is therefore common for seabeds of this type to have a cap of harder rock overlying softer material.

Some peculiarities of low-frequency sound propagation over calcarenite seabeds are considered in this paper based on normal mode theory, numerical modeling, and measurements of airgun signals made during a commercial seismic survey in Bass Strait, Australia, in 2011. In Sec. II, numerical modeling is used to investigate the narrowband sound filtering and waveguide dispersion properties of a shallow water acoustic channel over a calcarenite seabed. A simplified model of the channel is assumed here to analyze in detail the principal effects of sound propagation over such seabeds. Variations in modal attenuation and low-frequency transmission loss due to changes in water depth and/or geoacoustic properties of the sediment along the acoustic propagation path are considered. The effect of a thin layer of cap rock overlaying less cemented calcarenite is also modeled. This study is focused primarily on the peculiarities of longrange propagation in the water column, and consequently the characteristics of evanescent modes propagating along interfaces between water and sediment layers are not considered in detail.

Transmission loss (TL) measurements, conducted over the continental shelf in Bass Strait are discussed in Sec. III. The peculiarities of low-frequency sound propagation, including transmission loss and dispersion, observed in the experimental measurements are interpreted in Sec. III based on the numerical modeling results presented in Sec. II and numerical predictions for range-dependent bathymetry using an algorithm based on the parabolic approximation (Collis et al., 2008).

Potential implications of the observed and modeled sound propagation effects for predicting sound exposure of marine environments due to man-made sources of underwater noise used in offshore operations, such as seismic surveys, are discussed in Sec. IV.

\section{NUMERICAL MODELING OF LOW-FREQUENCY SOUND PROPAGATION}

The numerical predictions made in this section are based on the formulation given in Ellis and Chapman (1985) and the Wave Number Integration (WNI) transmission loss calculation method implemented in computer programs SCOOTER and FIELDS (Porter, 2007). The primary acoustic channel model used for numerical analysis consists of an isovelocity $\left(C_{w}=1500 \mathrm{~m} / \mathrm{s}\right)$ water layer of $110 \mathrm{~m}$ depth over a semi-infinite halfspace of semi-cemented calcarenite with a compressional wave speed of $2000 \mathrm{~m} / \mathrm{s}$, shear wave speed of $900 \mathrm{~m} / \mathrm{s}$ and density of $1900 \mathrm{~kg} / \mathrm{m}^{3}$. The acoustic source was assumed to be at $7 \mathrm{~m}$ below the sea surface and the receiver was placed on the seafloor. The choice of most of the modeling parameters was based on the conditions of experimental measurements and some estimates made from the interpretation of experimental results presented in Sec. III; however, the compressional and shear wave attenuations in the seabed were both set to zero in order to more clearly illustrate the effects of interest. More realistic attenuations are used in the comparison with experimental data given in Sec. III.

The transmission loss versus range and frequency calculated via WNI, and shown in the top panel of Fig. 1, reveals a series of almost regularly spaced narrow frequency bands of relatively low transmission loss, contrasting sharply with the background of high loss at other frequencies. The modulus of the Green's function shown in the bottom panel of Fig. 1 demonstrates that the bands of low transmission loss are located just above the critical frequencies of individual modes in a Pekeris waveguide having the same seabed compressional sound speed as the elastic bottom:

$$
F_{m}^{c r}=\frac{(m-1 / 2) C_{w}}{2 H\left(1-C_{w}^{2} / C_{p}^{2}\right)^{1 / 2}}
$$

where $H$ is water depth, $C_{w}$ is the water column sound speed, $C_{p}$ is the compressional wave speed in the seabed, and $m$ is the mode number. The Scholte wave propagating along the water-sediment interface can also be distinguished in the Green's function at low frequencies. The Scholte wave does not have a critical frequency, and its spectrum is governed by the source and receiver depth. The further the source and/ or receiver are from the interface, the narrower the spectrum of the Scholte wave will be.

The complex modal wave numbers $k_{m}$ can be calculated from the poles of the Green's function by finding roots of Eq. (B5) in Ellis and Chapman (1985): 


$$
1+e^{2 i \gamma H} R=0
$$

where $\gamma$ is the vertical component of the wave number in the water layer and $R$ is the plane-wave reflection coefficient of the seabed. The natural logarithm transformation of Eq. (2) gives

$$
2 \gamma_{m} H-\varphi-i \ln (|R|)=\pi(2 m-1),
$$

where $\varphi$ is the phase of the reflection coefficient. The term $2 \pi m$ on the right hand side arises from the $2 \pi$ ambiguity of the phase $\varphi$. Equation (3) is more robust than Eq. (2) with respect to finding complex roots and is easy to interpret. For $\gamma_{m}$ corresponding to grazing angles where $|R|=1$, Eq. (3) does not contain imaginary components and hence $\gamma_{m}$ is also real. Consequently, the modal horizontal wave numbers are real for any $m$ satisfying $\gamma_{m}<\omega / C_{w}$. For the case of interest here $\left(C_{s}<C_{w}\right.$, where $C_{s}$ is the shear wave speed in the seabed), this criterion is met for the water column modes, but not for the Scholte wave, which can be referred to as mode 0. Equation (3) is therefore suitable for finding the water column modes but not appropriate for finding the Scholte mode. The solution of Eq. (3) for the primary environmental model is shown in Fig. 2 for modes 1 to 4 . The reflection coefficient was calculated using the program
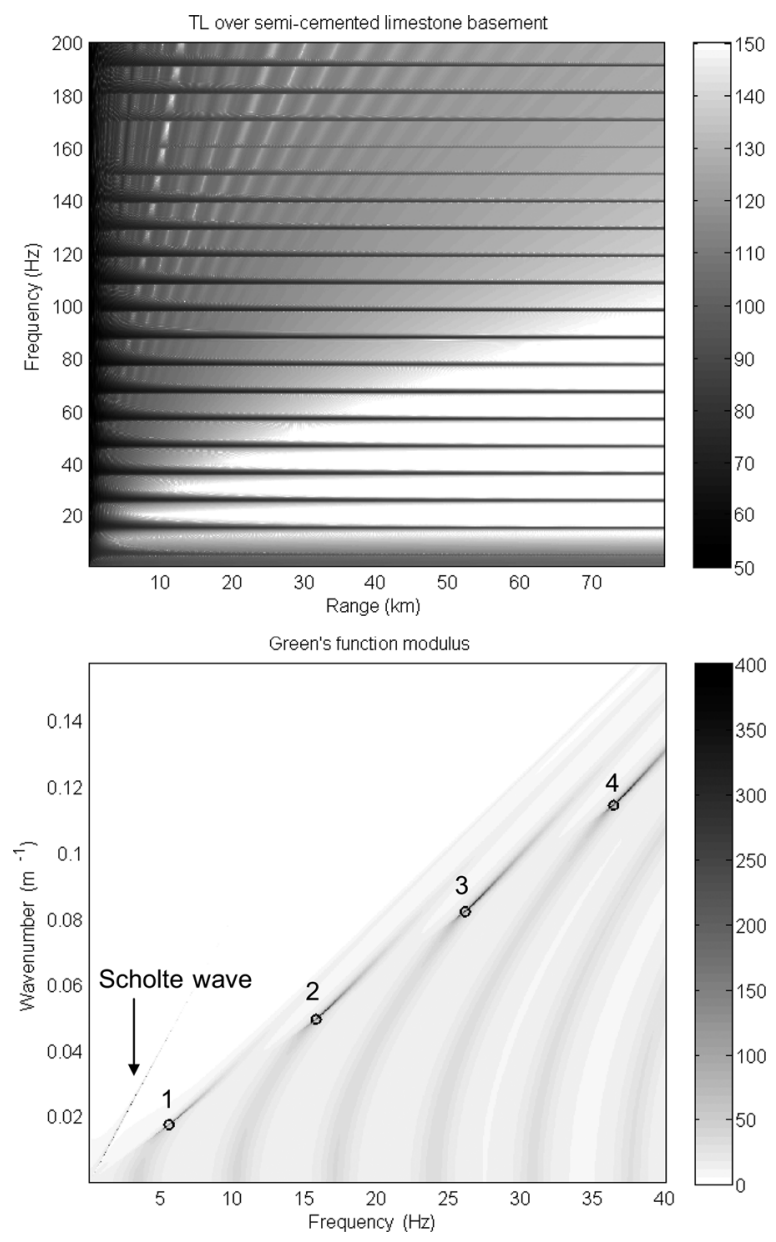

FIG. 1. (Top) Transmission loss over semi-cemented calcarenite without bulk acoustic attenuation and (bottom) modulus of Green's function. The circles indicate the critical frequencies of modes 1-4 with corresponding wave numbers.

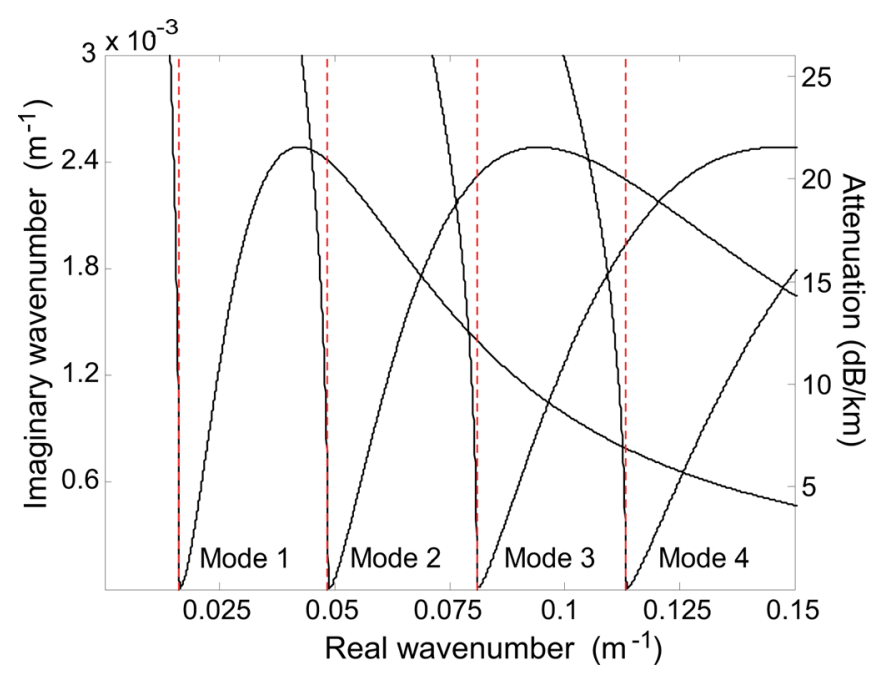

FIG. 2. (Color online) Imaginary versus real part of the horizontal wave number for modes 1 to 4 calculated for the primary model of a shallow water acoustic channel with an elastic seabed. The dashed lines indicate real wave numbers at the critical frequencies given by Eq. (1). The signal frequency varied from 4 to $40 \mathrm{~Hz}$.

BOUNCE by Porter (2007). The imaginary part of the modal horizontal wave numbers $k_{m}$, and consequently modal attenuation, are equal to zero only at the corresponding critical frequency and grow rapidly above it. Hence, the transfer function of a shallow water acoustic channel over a calcarenite seabed can be considered as a set of narrowband filters at low frequencies.

In the Pekeris model of sound propagation in shallow water over a fluid bottom, the transfer function of individual modes is dominated by higher frequency components well above the critical frequency, where the modal group velocity increases with frequency. This results in intra-modal frequency dispersion in which the higher frequency components of individual modes propagate faster than the lower frequency ones. For propagation over a calcarenite seabed this situation is reversed: As can be seen in Fig. 3, frequency

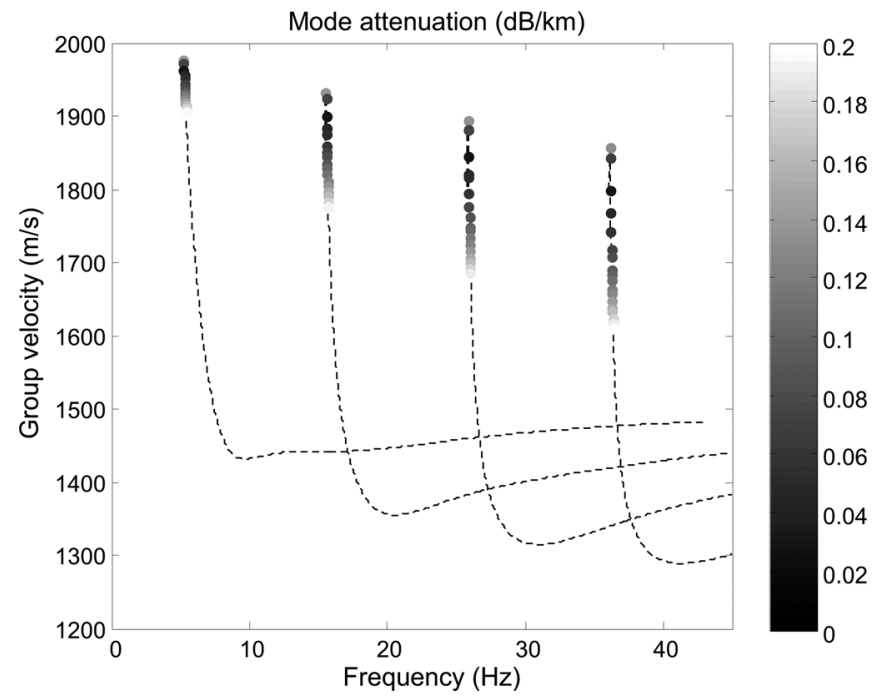

FIG. 3. Group velocities of modes 1-4 versus frequency calculated for the primary model of a shallow water acoustic channel over calcarenite. Modal attenuation is gray-scale coded. Values above $0.2 \mathrm{~dB} / \mathrm{km}$ are shown as a dotted line. 
components just above the critical frequency dominate the modal transfer function and have a modal group velocity that decreases rapidly with increasing frequency.

At its critical frequency and below, a mode is radiating (leaking) into the seabed, and its contribution to the sound intensity in the far field in the water column is minor. At frequencies higher than critical, the mode becomes trapped by the sound channel formed by the water column and seabed. As the frequency is increased, more of the mode energy is concentrated in the water column, which would lead to lower transmission loss. However, this effect is counteracted by the increase in modal attenuation with increasing frequency that occurs for frequencies above critical (Fig. 2). The result is that the minimum transmission loss for a given mode occurs at a frequency slightly higher than the modal critical frequency.

The modal critical frequencies shift with changes in the sea depth and compressional wave speed in the sediment. As a result, the frequency bands of low transmission loss of individual modes also change. The sensitivity of these bands to sea depth variations is illustrated in Fig. 4. The attenuation coefficient of mode 1 remains relatively small (less than $0.5 \mathrm{~dB} / \mathrm{km}$ ) only within a small range of depth variations of about $10 \mathrm{~m}$. Attenuation of the higher modes is even more sensitive to variations in sea depth. Consequently, the transfer function of an individual mode in a range dependent channel can be represented by a product of transfer functions of narrowband filters with varying central frequencies. If at least one of these frequency bands does not overlap with all others, then attenuation of this mode will be high.

The case of a layered elastic seabed, i.e., one consisting of sediment layers with distinct geoacoustic properties, is considered next. Of particular interest is the case of a basement consisting of relatively soft semi-consolidated sediment overlain by a thin $(1 \mathrm{~m})$ layer of cap rock. Geoacoustic parameters assumed for the basement are the same as those of the semicemented calcarenite used in the primary model. The top layer is assumed to consist of well-cemented calcarenite (limestone) with a compressional wave speed of $2600 \mathrm{~m} / \mathrm{s}$, shear wave speed of $1200 \mathrm{~m} / \mathrm{s}$, and density of $2200 \mathrm{~kg} / \mathrm{m}^{3}$.

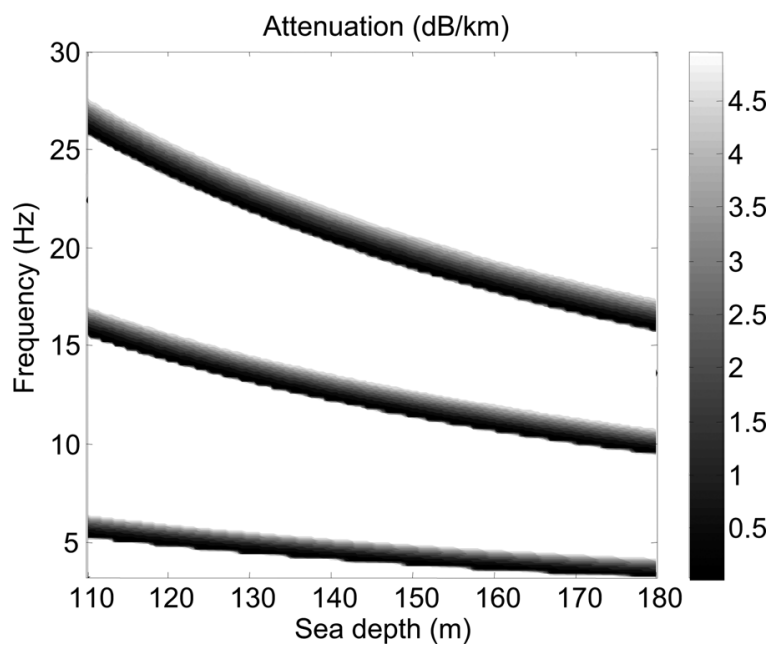

FIG. 4. Attenuation of modes 1 to 3 versus water depth and frequency calculated for the primary model of the acoustic channel.
In contrast to the halfspace model of the seabed with uniform geoacoustic properties assumed in the primary model, the reflection coefficient from a layered seabed is frequency dependent. At very low frequencies, when the layer thickness is negligible compared to the acoustic wavelength, the cap rock is almost transparent to sound waves and hence the reflection coefficient is governed by the geoacoustic properties of the basement. However, the effect of the cap rock layer increases rapidly with frequency. If the wavelength remains much larger than the top layer thickness, then the major effect of the cap rock is a rapid reduction of the reflection coefficient at the basement critical angle as the frequency increases (Fig. 5). As a result, the effect of the imaginary part of Eq. (3) on modal wave numbers increases with frequency, which leads to a significant increase in modal attenuation, including at the critical frequencies (Fig. 6). In other words, the cap rock layer works as a low-pass filter at low frequencies.

\section{LOW-FREQUENCY TRANSMISSION LOSS IN BASS STRAIT}

\section{A. Experimental measurements}

Measurements of the transmission loss of airgun signals from an offshore seismic exploration survey were made in 2011 in the western part of Bass Strait as part of an 8-month sea noise monitoring and blue whale tracking program supported by Origin Energy. The measurements were made using an array of four autonomous sea noise recorders deployed on the seafloor on the continental shelf near the continental slope. Three sea noise recorders were set on the seafloor at the vertices of a triangle with approximately $5 \mathrm{~km}$ sides and the fourth recorder was placed at the array center (Fig. 7). To extend the duration of autonomous operation up to 8 months, the recorders were programmed to make $500 \mathrm{~s}$ continuous recordings starting every $900 \mathrm{~s}$. The sampling frequency was $6 \mathrm{kHz}$ and the frequency band was limited by a low-pass anti-aliasing filter with a cut-off frequency at 2.8 $\mathrm{kHz}$. The receive channels of all four recorders were calibrated across the entire recording frequency band prior to

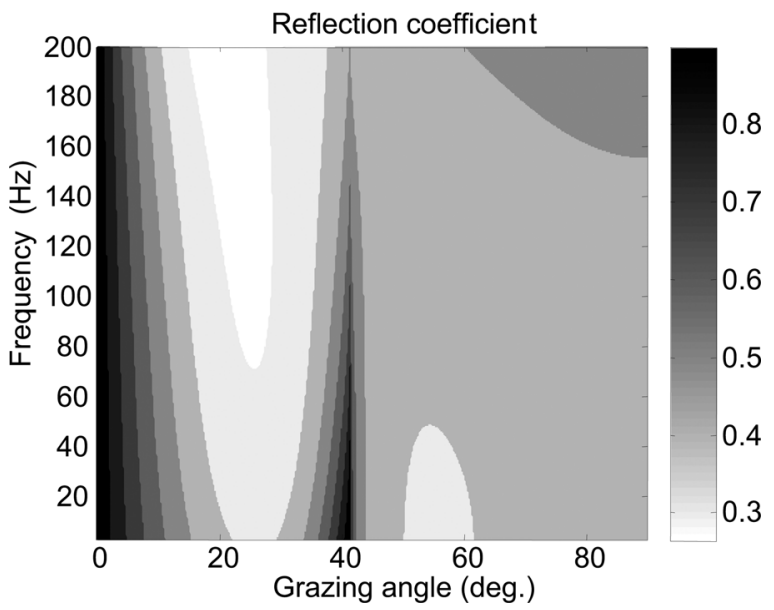

FIG. 5. Reflection coefficient from a $1 \mathrm{~m}$ layer of cap rock overlaying semicemented calcarenite versus grazing angle and frequency. 


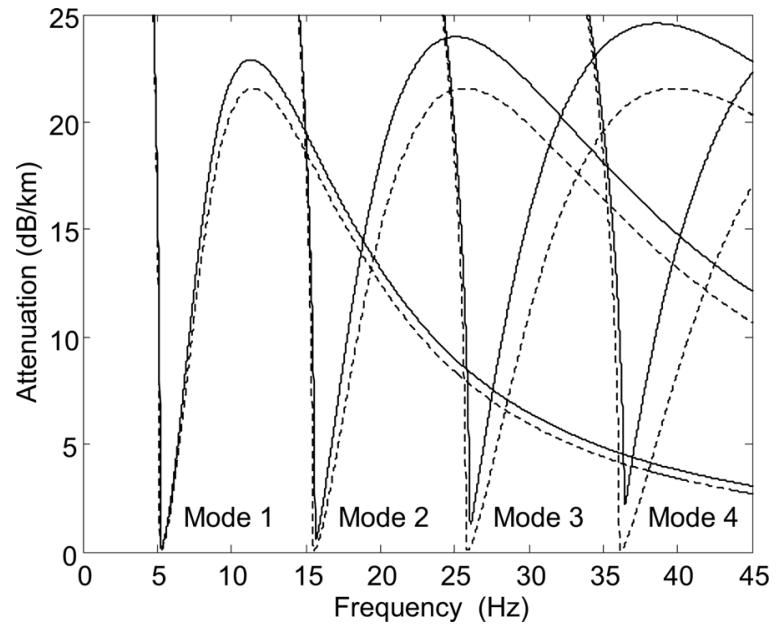

FIG. 6. Attenuation of modes 1 to 4 in a shallow water channel over an elastic seabed with (solid lines) and without (dashed lines) $1 \mathrm{~m}$ layer of cap rock overlaying semi-cemented calcarenite.

deployment so that the acoustic pressure was measured in absolute units.

Eleven parallel seismic transects were made southeast of the hydrophone array along the edge of the continental shelf. Six transects (referred to as inshore) were located further from the continental slope and the other five (offshore) lay close to the shelf edge. The easternmost inshore and offshore transects are shown in Fig. 7. The length of each transect was approximately $33 \mathrm{~km}$ and the distance to the receiver array varied from about $40 \mathrm{~km}$ to nearly $75 \mathrm{~km}$. During all transects the seismic vessel sailed towards the hydrophone array. Seismic shots were produced by a rectangular array of airguns with a total volume of $50640 \mathrm{~cm}^{3}\left(3090 \mathrm{in.}^{3}\right)$ towed at about $7 \mathrm{~m}$ below the sea surface. The shot repetition interval was $8 \mathrm{~s}$.

Although the spatial separation of the inshore and offshore seismic transects was not large, the bathymetry along the acoustic paths was noticeably different. Variations in sea depth along the path from the inshore transects to receivers 1 , 2 , and 3 were similar and stayed within approximately

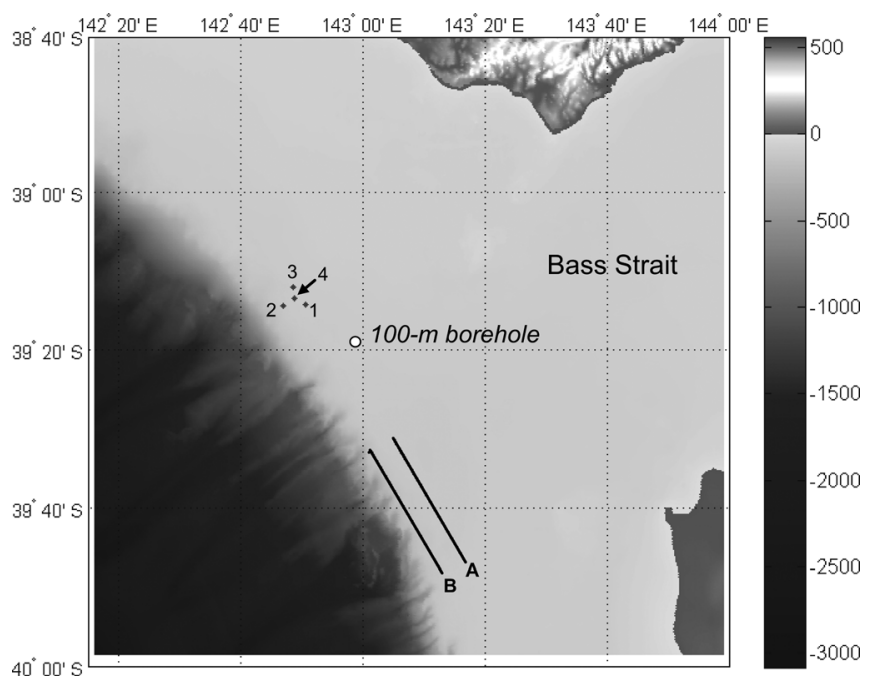

FIG. 7. Location of the hydrophone array (1 to 4) and the easternmost inshore (A) and offshore (B) seismic transects in Bass Strait. The white circle shows the location of a $100 \mathrm{~m}$ borehole made as part of a geotechnical survey.

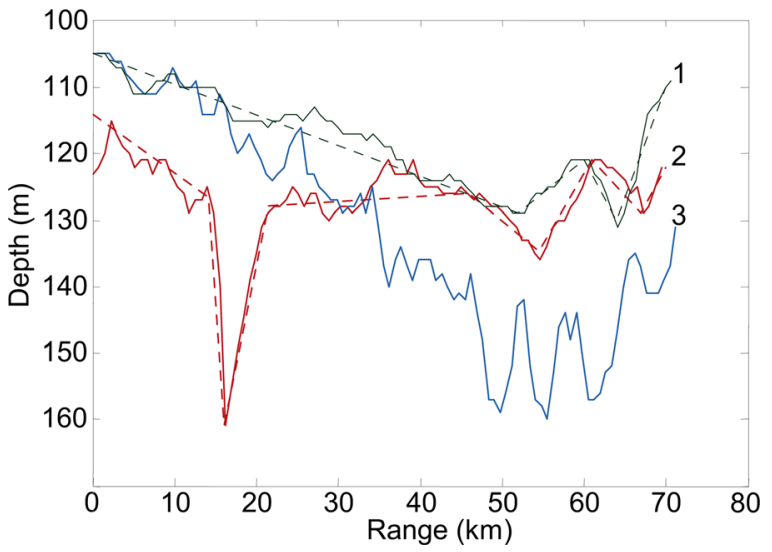

FIG. 8. (Color online) Bathymetry along the acoustic paths: (1) from receiver 1 to the starting point (southernmost) of inshore transect A; (2) from receiver 2 to the starting point of inshore transect $A$; and (3) from receiver 3 to the starting point of offshore transect B. Bathymetry data were taken from the Australian bathymetry and topography grid (Geoscience Australia, 2009). The dashed lines show piecewise linear approximation of the bathymetry profiles used for PE modeling of transmission loss.

$115 \pm 10 \mathrm{~m}$ (Fig. 8). The path from the inshore lines to receiver 2 went over a deep trough, crossing the edge of the continental shelf at distances from about $14 \mathrm{~km}$ to $20 \mathrm{~km}$ from the receiver. The seafloor along the acoustic paths from the offshore lines to all four receivers was noticeably sloping and generally rougher than that from the inshore lines (Fig. 8).

An analysis of the airgun signals recorded by the receive array revealed the following peculiarities of sound propagation:

(1) The spectrum of signals received from the airgun array, i.e., a broadband impulsive source, contained noticeable energy components only within a few narrow frequency bands and no energy above approximately $35 \mathrm{~Hz}$ (Fig. 9);

(2) The signal spectrogram revealed frequency dispersion within these frequency bands, with the lower frequencies propagating significantly faster than the higher ones (Fig. 9);

(3) Airgun signals from the offshore seismic transects were not found in the noise recordings made by any of the

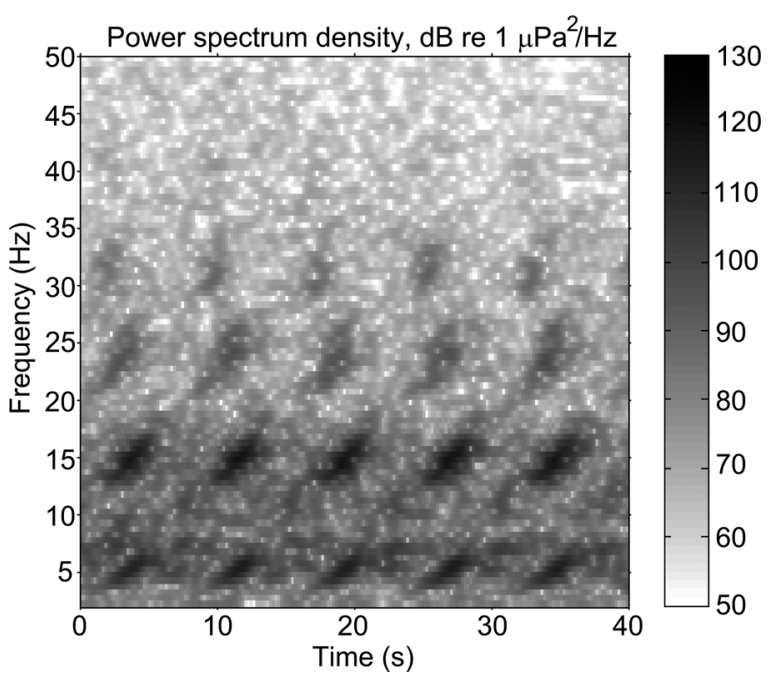

FIG. 9. Spectrogram of a 40-s recording fragment made on receiver 1 showing five airgun signals from the inshore transect. 
four receivers, despite the ranges involved being similar to those for the inshore transects;

(4) Signals from the inshore transects could only be detected in receiver 2 recordings at the shortest distances of about $40 \mathrm{~km}$, whereas they were observed at receivers 1,3 , and 4 at all distances, and their levels did not differ much at similar ranges.

Sound transmission loss was analyzed by measuring the average Energy Spectrum Density (ESD) of five consecutive shots received around the middle of each $500 \mathrm{~s}$ continuous recording. The distance of the airgun array to each noise recorder was estimated from the seismic survey navigation data at the time of the third shot. To determine the source level and spectrum, the waveform of the signal transmitted by the airgun array was modeled in the far field in the direction to the receiver array using the method described in Duncan et al. (2008). The transmitted signal model was validated by comparing the modeled acoustic pressure for the vertically downward direction with the array calibration waveform provided by the seismic contractor. The ESD of the transmitted signal has a maximum level of approximately $222 \mathrm{~dB}$ re $1 \mu \mathrm{Pa}^{2} . \mathrm{s} / \mathrm{Hz}$ at $1 \mathrm{~m}$ at about $8 \mathrm{~Hz}$ followed by a relatively gradual decrease with frequency up to $70-80 \mathrm{~Hz}$ with some fluctuations (Fig. 10). The rate of sound attenuation with range was considerably higher than that expected for a $100 \mathrm{~m}$ underwater channel over a fluid bottom, even in the frequency band of the ESD maximum at about $14 \mathrm{~Hz}$ (Fig. 11). At this frequency the attenuation rate could be reasonably well approximated by cylindrical spreading loss with an additional exponential decay of $0.5 \mathrm{~dB} / \mathrm{km}$. This result was obtained from the best fit to the ESD values of the airgun signals recorded by receivers 1 and 3 . The change in the transmission loss with range at receiver 4 was less regular.

\section{B. Interpretation of experimental results}

To explain the peculiarities of low-frequency sound propagation observed over the continental shelf at the western edge of Bass Strait, an outline of the geoacoustic model of the seafloor was constructed based on the following supplementary data and assumptions:

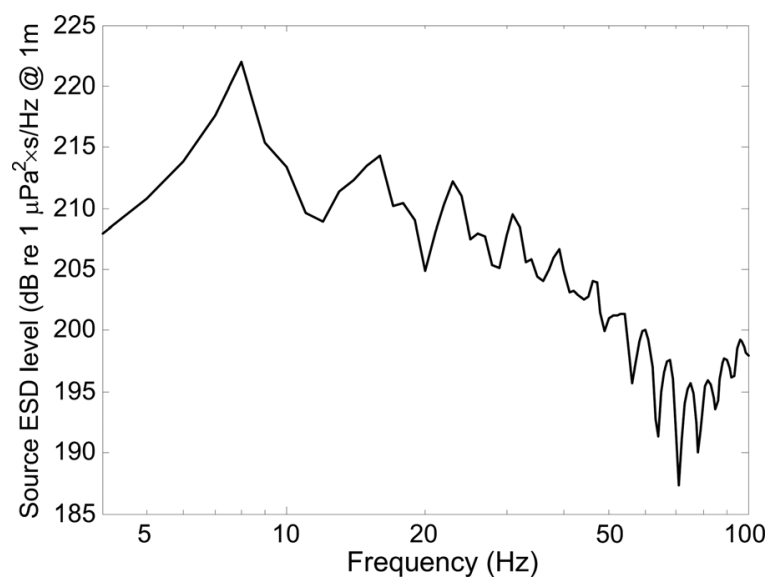

FIG. 10. Energy spectrum density of the signal from the airgun array at $1 \mathrm{~m}$ from the array center modeled for the far field.

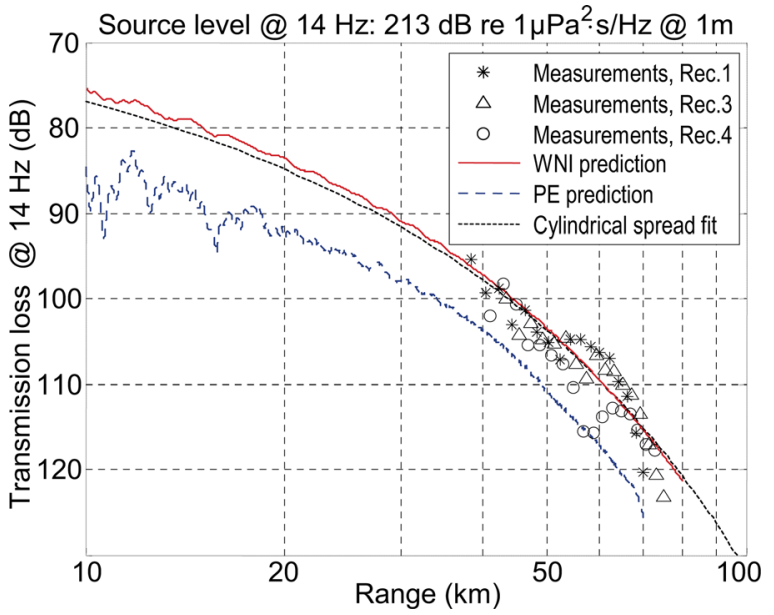

FIG. 11. (Color online) Measured (signs), approximated by an empirical curve (dotted) and numerically modeled (WNI - solid, PE - dashed) transmission loss at $14 \mathrm{~Hz}$. The source ESD level is estimated from the transmitted signal model to be $213 \mathrm{~dB}$ re $1 \mu \mathrm{Pa}^{2} \mathrm{~s} / \mathrm{Hz}$ at $1 \mathrm{~m}$.

(1) Geotechnical data from boreholes. A number of boreholes were made at the western edge of Bass Strait in 2003 as part of the Thylacine field development in the Otway Basin conducted by Woodside Energy Ltd. The bores were drilled to determine the geotechnical properties of the sediments in the development area (Fugro, 2004). The boreholes were located not far from the sound propagation paths considered in this article. All bores indicated a cap rock of well cemented calcarenite approximately $1 \mathrm{~m}$ thick underlain by a variably cemented mixture of calcarenite and sand. Laboratory analysis of the sediments taken from the deepest $(100 \mathrm{~m})$ borehole, indicated on the map in Fig. 7, revealed that the saturated density of slightly cemented sediments varied from 1800 to $1900 \mathrm{~kg} / \mathrm{m}^{3}$ and the small strain shear modulus varied unevenly but increased in general from about $400 \mathrm{MPa}$ in the upper layers to $850 \mathrm{MPa}$ at $100 \mathrm{~m}$. Based on these data, one can estimate the shear wave speed to vary from about $450 \mathrm{~m} / \mathrm{s}$ to $650 \mathrm{~m} / \mathrm{s}$.

(2) Head wave measurements. Airgun signals from another seismic survey in Bass Strait, conducted in 2006, were recorded at relatively short distances on a bottom mounted hydrophone deployed near the northern end of the inshore transects. An analysis of the signal waveform received at different distances revealed an intense lowfrequency wave, which propagated considerably faster than the waterborne waves that were apparent at higher frequencies (Fig. 12). The range dependence of the arrival time of this wave relative to the arrival time of the water-borne wave indicated that it was a head wave propagating along an interface of high acoustic impedance contrast between different sediments at a depth of approximately $1000 \mathrm{~m}$ below the seafloor. The compressional wave speed in the underlying acoustic medium was estimated to be about $3800 \mathrm{~m} / \mathrm{s}$. The medium can be considered as a rock basement in the geoacoustic model. Arrivals of lower frequency signals after the primary head wave, but before the waterborne wave can also be distinguished in the signal waveform recorded at 


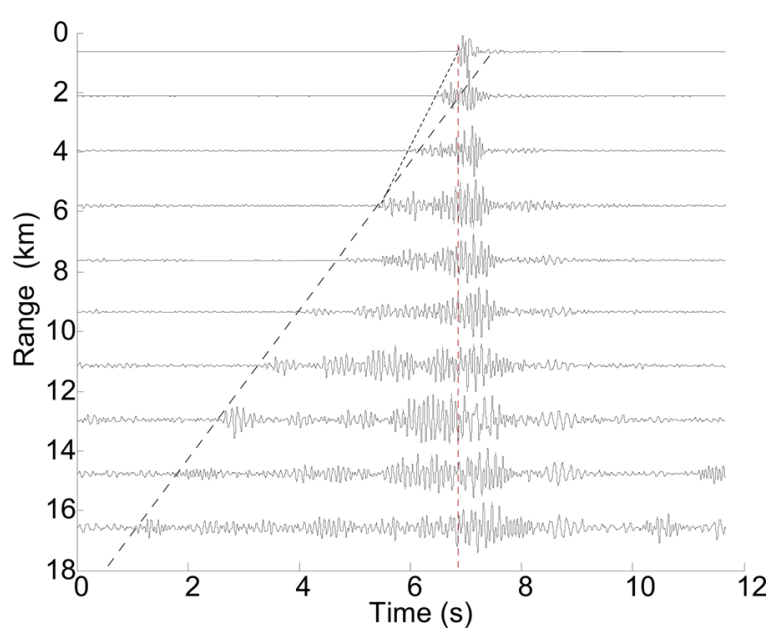

FIG. 12. (Color online) Low-pass $(<20 \mathrm{~Hz})$ filtered airgun signals received on a bottom-mounted hydrophone at different distances from the signal source. The waveforms are aligned at the arrival time of high-frequency waterborne waves (vertical dotted line). The dashed line indicates the arrival times of the head wave propagating along the interface of the rigid basement at a depth of approximately $1000 \mathrm{~m}$ below the seafloor.

different distances. These signal arrivals most likely correspond to the head waves propagating along interfaces between the upper sediment layers. However, interference between these arrivals prevented them from being used to estimate the sound speeds in the upper sediment layers.

(3) The compressional wave speed in the upper layers of sediments can be estimated from the critical frequencies of individual modes using Eq. (1). For the mean sea depth of approximately $115 \mathrm{~m}$ along the acoustic paths from the inshore seismic transect to the receiver array and the mean sound speed in water of $1509 \mathrm{~m} / \mathrm{s}$, the compressional wave speed derived from the critical frequencies of modes 1 and 2 at approximately 5 and $14 \mathrm{~Hz}$, respectively, is expected to be within $2000-2100 \mathrm{~m} / \mathrm{s}$.

In the absence of geoacoustic data below $100 \mathrm{~m}$ and without any evidence of another interface of high acoustic impedance contrast above the rock basement, it was assumed that the sediments from 100 to $1000 \mathrm{~m}$ consisted of a semicemented mixture of calcarenite and sand with depth invariant geoacoustic parameters similar to those at $100 \mathrm{~m}$. As a result, the geoacoustic model used for numerical modeling of sound propagation and interpretation of the measured results was assumed to have the parameters shown in
Table I, with some values adjusted through fitting to measurement results.

The WNI method provides accurate numerical predictions of the sound field for environments with arbitrary fluid and elastic layering but is applicable only to rangeindependent environments. The WNI program, SCOOTER, was therefore used to model the transmission loss versus frequency and range only for the paths from the inshore transects, ignoring the relatively small variations in bathymetry along the acoustic paths to receivers 1, 3, and 4, and assuming the sea depth to be constant and equal to the average value of $115 \mathrm{~m}$. The sound speed profile in the water column was obtained from CTD measurements in the area: It had a moderate and slightly varying negative gradient with a sound speed of about $1514 \mathrm{~m} / \mathrm{s}$ at the sea surface and $1505 \mathrm{~m} / \mathrm{s}$ at the bottom.

Some geoacoustic parameters in the numerical model were manually varied in order to find a good match between the modeled and measured transmission losses. The most uncertain parameters of the assumed geoacoustic model were the attenuation coefficients of both compressional and shear waves in the slightly and semi-cemented sediments. Modeling showed that the transmission loss at the modal critical frequencies are highly sensitive to variations in these coefficients. The values shown in Table I were found from the best fit of modeled results to the measured transmission loss at the critical frequencies of modes 1 and 2 . The other geoacoustic parameters significantly affecting transmission loss are the compressional and shear wave speeds in the layer of semi-cemented sediments. Alteration of these parameters in the numerical model to find a good match between the measured and predicted transmission losses resulted in values that were similar to the estimates based on the geotechnical data.

Once the geoacoustic parameters were estimated based on the geotechnical data and a comparison of the measurement results with the WNI numerical predictions, the transmission loss was modeled for the range-dependent environment using a piecewise linear approximation of the varying bathymetry profiles (Fig. 8) and a parabolic equation (PE) solution recently developed by Collis et al. (2008). Solutions between WNI and PE calculations were comparable for the range-independent case.

The transmission loss at the critical frequency of mode 2 , predicted numerically using the geoacoustic parameters given in Table I, is compared with the experimental measurements in Fig. 11. The agreement is reasonably good for

TABLE I. Geoacoustic parameters of the seafloor model used for numerical modeling of sound propagation.

\begin{tabular}{|c|c|c|c|c|c|c|}
\hline \multirow[b]{2}{*}{ Material } & \multirow[b]{2}{*}{$\begin{array}{l}\text { Thickness } \\
\text { (m) }\end{array}$} & \multirow[b]{2}{*}{$\begin{array}{l}\text { Density, } \\
\left(\mathrm{kg} / \mathrm{m}^{-3}\right)\end{array}$} & \multicolumn{2}{|c|}{ Compressional wave } & \multicolumn{2}{|c|}{ Shear wave } \\
\hline & & & $\begin{array}{l}\text { Velocity } \\
(\mathrm{m} / \mathrm{s})\end{array}$ & $\begin{array}{c}\text { Attenuation } \\
{[\mathrm{dB} /(\mathrm{kHz} \mathrm{m})]}\end{array}$ & $\begin{array}{l}\text { Velocity } \\
(\mathrm{m} / \mathrm{s})\end{array}$ & $\begin{array}{c}\text { Attenuation } \\
{[\mathrm{dB} /(\mathrm{kHz} \mathrm{m})]}\end{array}$ \\
\hline Well-cemented calcarenite & 1 & 2200 & 2600 & 0.2 & 1200 & 0.4 \\
\hline Slightly to semi-cemented sand/ calcarenite & 100 & 1900 & 2100 & 0.12 & 550 & 0.25 \\
\hline Semi-cemented sand/calcarenite & 900 & 1900 & 2200 & 0.12 & 650 & 0.25 \\
\hline Basement (rock) & $\mathrm{n} / \mathrm{a}$ & 3000 & 3800 & 0.1 & 1900 & 0.2 \\
\hline
\end{tabular}


the WNI prediction, especially for the measurements made by receivers 1 and 3 . The PE prediction resulted in slightly higher transmission loss, about $5 \mathrm{~dB}$ at $14 \mathrm{~Hz}$. Numerical predictions of the transmission loss of mode 1 were also satisfactory (top panel in Fig. 13), although the frequency of minimum transmission loss predicted by PE was slightly higher than that measured from the experimental data. The frequency band of the maximum intensity of mode 3 at about $24 \mathrm{~Hz}$ was accurately predicted by both numerical models; however, the range-independent scenario modeled by WNI resulted in noticeably lower transmission loss around the critical frequency of mode 3 , while the PE method applied to the range-dependent bathymetry resulted in an accurate prediction of the transmission loss. Mode 4 was seen in ambient noise at $30-31 \mathrm{~Hz}$ only at the shortest distances of about $40 \mathrm{~km}$. Its frequency band and transmission loss were not correctly predicted by either numerical model. Such disagreement is not surprising for the WNI modeling because it assumes range-independent bathymetry, and the effect of varying sea depth on the transmission loss increases with

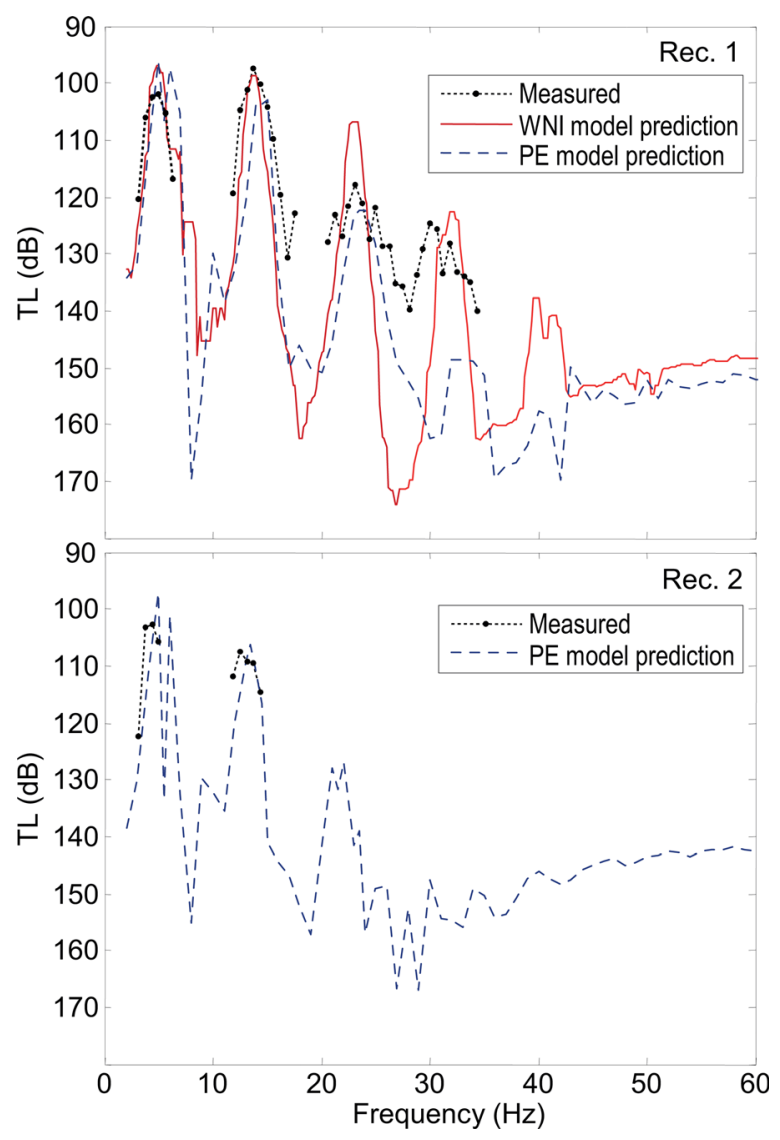

FIG. 13. (Color online) (Top) Transmission loss as a function of frequency determined from airgun signals measured by receiver 1 at a distance of approximately $40 \mathrm{~km}$ (dotted line). Values of low SNR (below $1 \mathrm{~dB}$ ) are not shown. The solid line is a numerical prediction using the WNI method and a range-independent bathymetry model with the geoacoustic parameters given in Table I. The dashed line shows the numerical prediction by the PE method applied to the same acoustic environment model but with the rangedependent bathymetry shown by the dashed line in Fig. 8. (Bottom) Same as top figure but for the signal measured at receiver 2. The PE numerical prediction shown here used the bathymetry model shown by the dashed line (2) in Fig. 8. mode number and its critical frequency, as shown in Sec. II. The most likely reason for the disagreement between the measured and PE modeled transmission losses was that the bathymetry profile and geoacoustic model assumed in the sound propagation model were somewhat different from the actual geoacoustic environment, which is more critical for higher modes interacting with deeper sediment layers.

Transmission loss over the acoustic path to receiver 2 was modeled using only the PE method because the sea depth along this path was significantly variable. The PE prediction of transmission loss around the critical frequencies of modes 1 and 2 at $40 \mathrm{~km}$ were in a good agreement with the measurement results (bottom panel in Fig. 13). The airgun signal at the critical frequency of mode 3 could not be distinguished in ambient noise, so the numerical prediction could not be compared with the measurement data, although the trend predicted by the PE solution is consistent with the results found for receiver 1 .

\section{CONCLUSIONS}

Low-frequency acoustic propagation over elastic seabeds with shear wave speeds less than the water column sound speed is characterized by relatively low transmission loss only in narrow frequency bands. Each of these bands occurs just above the critical frequency of a mode and is a result of two counteracting factors: An increase in modal attenuation and an increase in mode amplitude in the water column that occur as frequency is raised above the modal critical frequency. The effect of a thin cap-rock layer of relatively hard material overlaying the elastic halfspace is to increase modal attenuation at low frequencies, resulting in higher transmission losses near the modal critical frequencies. This effect increases with increasing frequency.

Within a low-loss band the group velocity decreases with increasing frequency, resulting in peculiar intramodal frequency dispersion of propagating signals compared to that in a shallow water acoustic channel over a fluid bottom. Although this dispersion is qualitatively predicted by the numerical model considered in this paper, the accuracy of dispersion measurements was not high enough to make a quantitative comparison with theoretical predictions. Moreover, the numerical model predicted that the group velocity should gradually decrease with increasing mode number, which was not observed in the experimental data.

For sea depth varying slightly along the acoustic path, an approximate range-independent model of the acoustic environment with a layered elastic model of the seabed covered with a $1 \mathrm{~m}$ thick cap-rock layer, provided an accurate prediction of the transmission loss at the critical frequencies of modes 1 and 2 but underestimated the transmission loss of higher modes. The PE solution was capable of more or less accurate prediction of transmission loss at modes 1 to 3 critical frequencies but failed in predicting for higher modes, which was most likely due to an insufficiently accurate geoacoustic model of the seabed. Another reason for the 
discrepancy could be range dependence of the sediment layering and geoacoustic parameters in the real environment, while they were assumed to be range-independent in the model.

For an acoustic path over noticeably varying bathymetry, the PE method predicted accurately the transmission loss around the critical frequency of modes 1 and 2. However, the comparison of measured and modeled results was made only at the shortest distances of about $40 \mathrm{~km}$, where the airgun signal could be distinguished from the background noise and its energy spectrum level could be accurately measured. Experimental data at shorter distances would be very useful for validating the acoustic propagation model.

Understanding the propagation of low-frequency underwater sound over continental shelf seabeds is very important to the prediction of sound levels from all low-frequency sources but particularly for the prediction of levels due to offshore seismic surveys. These surveys utilize arrays of airguns that have source spectra similar to that shown in Fig. 10 and produce large amounts of low-frequency acoustic energy. According to Geosciences Australia (2011), an average of $22143 \mathrm{~km}^{2} / \mathrm{yr}$ of 2-D seismic surveys and $23193 \mathrm{~km}^{2} / \mathrm{yr}$ of 3-D seismic surveys were made in Australian waters from 2005 to 2009 (the last year for which statistics are currently available), making these surveys a substantial source of lowfrequency underwater sound. The potential environmental impacts of these surveys depend to a large extent on the propagation of sound from the noise sources. The work described here shows that typical Australian continental shelf seabeds result in relatively poor propagation of low-frequency sound, except in narrow frequency bands. It is therefore necessary that modeling be carried out with a fine enough resolution to capture these bands.

\section{ACKNOWLEDGMENTS}

The authors thank Origin Energy Ltd. for financial and logistical support for the acoustic measurements, for providing details of the seismic survey, and for providing seabed geotechnical data.
Arvelo, J. I., and Überall, H. (1990). "Adiabatic normal-mode theory of sound-propagation including shear-waves in a range-dependent oceanfloor," J. Acoust. Soc. Am. 88, 2316-2325.

Brekhovskikh, L. M. (1960). Waves in Layered Media (Academic Press, New York), Chap. 1.

Chotiros, N. P., and Isakson, M. J. (2010). "Calcarenite as a poroelastic granular medium," in Proceedings of Oceans 2010 IEEE Conference, Sydney, Australia, 24-27 May, pp. 1-5.

Collis, J. M., Siegmann, W. L., Jensen, F. B., Zampolli, M., Küsel, E. T., and Collins, M. D. (2008). "Parabolic equation solution of seismoacoustics problems involving variations in bathymetry and sediment thickness," J. Acoust. Soc. Am. 123, 51-55.

Duncan, A. J., Gavrilov, A., and Hu, T. (2008). "Using offshore seismic surveys as sources of opportunity for geoacoustic inversion," in Proceedings of the European Conference on Underwater Acoustics, edited by M. E. Zakharia, Paris, June 29 to July 4, pp. 255-260.

Duncan, A. J., Gavrilov, A., and Li, F. (2009). "Acoustic propagation over limestone seabeds," in Acoustics 2009: Research and Consulting, Proceedings Australasian Acoustical Societies' Conference, edited by T. McMinn, Adelaide, Australia, 23-25 November 2009, p. 6.

Ellis, D. D., and Chapman, D. M. F. (1985). "A simple shallow water propagation model including shear wave effects," J. Acoust. Soc. Am. 78, 2087-2095.

Ewing, W. M., Jardetsky, W. S., and Press, F. (1957). Elastic Waves in Layered Media (McGraw-Hill, New York), 380 p.

Fugro (2004), "Draft geotechnical report, Otway gas project, final platform geotechnical investigation, offshore Victoria, Australia," Fugro Survey Report No. HY 16608, Fugro Engineers BV Report No. N4349/02.

Geoscience Australia (2009). "Australian bathymetry and topography grid, June 2009," Canberra: Geoscience Australia, http://www.ga.gov.au/meta/ ANZCW0703013116.html (Last viewed August 29, 2012).

Geoscience Australia (2011). "Oil and Gas Resources of Australia 2009," Geoscience Australia, Canberra (Geocat:71530), http://www.ga.gov.au/ products-services/publications/oil-gas-resources-australia/2009/seismic.html (Last viewed August 29, 2012).

Katsnelson, B., Petnikov, V., and Lynch, J. (2012). Fundamentals of Shallow Water Acoustics (Springer, New York), $540 \mathrm{p}$.

Lobanov, V. N., and Petukhov, Y. V. (1993). "Space-frequency distribution of the intensity of wide-band sound in a shallow sea," Acoust. Phys. 39(6), 574-581.

Pekeris, C. L. (1948). "Theory of propagation of explosive sound in shallow water," Geol. Soc. Am. Mem. 27, 205 p.

Porter, M. B. (2007), “Acoustics toolbox," http://oalib.hlsresearch.com/FFP/ index.html (Last viewed August 27, 2012)

Tolstoy, I., and Clay, C. S. (1966). Theory and Experiments in Underwater Acoustics (McGraw-Hill, New York), Chap. 4.

Victor, A. S., Spitznog, F. L., and McLeroy, E. G. (1965). "Propagation at short ranges of elastic waves from an impulsive source in a shallow fluid overlying a layered elastic solid,” J. Acoust. Soc. Am. 37, 894-898. 